\title{
MORPHOMETRIC ANALYSIS OF FORAMEN MAGNUM IN NORTH INDIAN POPULATION
}

\author{
Poonam Srivastava, Medha Das, Shirin Jahan \\ Department of Anatomy, Rama Medical College Hospital \& Research Centre, Mandhana, Kanpur, UP
}

\begin{abstract}
Introduction: Foramen magnum is a large opening located in the occipital bone of the skull. The morphometric analysis of foramen magnum is clinically and surgically important because vital structures passing through it may suffer compression such as in cases of achondroplasia, brain herniation and meningiomas.
\end{abstract}

Objectives: To study morphometric analysis of foramen magnum in dry human skulls and to measure its anteroposterior diameter, transverse diameter and foramen magnum index.

Material \& Methods: 100 dried human skulls of unknown age and sex were obtained from Department of Anatomy, Rama Medical College and GSVM Medical College, Kanpur, Uttar Pradesh, India. Deformed samples were excluded. Different parameters were measured with the help of Vernier caliper.

Results: The mean antero-posterior diameter of foramen magnum was $33.79 \mathrm{~mm}$. The maximum antero-posterior diameter of foramen magnum was $40 \mathrm{~mm}$ and minimum antero-posterior diameter was $28.2 \mathrm{~mm}$. The mean transverse diameter of foramen magnum was $28.30 \mathrm{~mm}$. The maximum transverse diameter of foramen magnum was $36 \mathrm{~mm}$ and minimum transverse diameter was $21.5 \mathrm{~mm}$. The mean index of foramen magnum was $84.14 \mathrm{~mm}$.

Conclusion: The morphometric analysis of foramen magnum and its variation is important not only for anatomists but also important to the anesthetists, neurosurgeons, orthopedicians and radiologists ; while planning and performing cranio-vertebral junction procedures.

Keywords: Antero-posterior diameter, transverse diameter, foramen magnum index

\section{INTRODUCTION}

The posterior part of cranial base is largely occupied by occipital bone. Its most prominent feature is foramen magnum. It is the largest bony foramen in the base of skull. It lies in antero-median position and leads into the posterior cranial fossa. It is oval and wider behind with its greater diameter being anteroposterior diameter [1]. Foramen magnum provides a wide communication between posterior cranial fossa and the vertebral canal. The major structure passing through this large foramen are lower end of medulla oblongata with meninges, vertebral arteries, spinal accessory nerve, anterior and posterior spinal arteries, apical ligament of dens and tectorial membrane. Anteriorly, the margin of foramen magnum is slightly overlapped by the occipital condyles, which articulate with the first cervical vertebra to form atlanto-occipital joint [1]. In the midline, the anterior margin of the foramen magnum is called basion and the posterior margin is called opisthion [2]. Foramen magnum is surrounded by different parts of the occipital bone. The squamous part lies behind and above, basilar part in front and a condylar part on either side [3].

Diameters of foramen magnum have been reported to be about $35 \mathrm{~mm}$ antero-posterior and $30 \mathrm{~mm}$ transverse [4]. Dimensions of foramen magnum differ in each individual skull. Depending on the dimensions there are various types of shapes of foramen magnum. It can be oval, egg shaped, rounded, tetragonal, pentagonal, hexagonal and 
irregular [5]. Most common shape observed is oval shape. The importance of variations in shape is due to its effects on the vital structures passing through it. Its shape also plays an important role in deciding various surgical approaches in this region. Dimensions of the foramen magnum has clinical as well as surgical importance because the vital structures that pass through it may get compressed in various conditions such as foramen magnum stenosis, achondroplasia, foramen magnum brain herniation and foramen magnum meningiomas. These may result into lifethreatening respiratory complications [6]. The knowledge of diameters of foramen magnum is needed to determine some malformations such as Arnold Chiari syndrome, in which there is expansion of transverse diameter [7].

The abnormalities of the cranio-vertebral junction can be congenital [8]. The progress in the neuroimaging techniques to diagnose cranio-vertebral abnormalities accurately has increased interest and scope for cranio-vertebral surgeries. Such surgeries are a challenging task for the neurosurgeons, because of the close relation of vascular and neural structures to foramen magnum. Advances in skull base surgeries such as 'far lateral transcondylar approach' have improved the better and wider access of surgical exposure leading to successful surgeries. To perform such surgeries, prior analysis of the morphometric dimensions of foramen magnum is essential [9]. The diameters of the foramen magnum are greater in male than female hence the study about foramen magnum dimensions can be used in the field of forensic medicine to determine sex in the medico legal conditions as in aircrafts injuries and war fare injuries [10].

The morphometric analysis of foramen magnum and its variation is important not only for anatomists but also important to the anesthetists, neurosurgeons, orthopedicians, radiologists, while planning and performing cranio-vertebral junction procedures [11].

The dimensions of the foramen magnum are clinically and surgically important because the vital structures that pass through it may suffer compression in case of foramen magnum achondroplasia, foramen magnum brain herniation, foramen magnum meningiomas [11].

\section{MATERIALS AND METHODS}

100 dried human skulls of unknown age and sex were obtained from Department of Anatomy, Rama Medical College \& GSVM Medical College, Kanpur, Uttar Pradesh, India. Deformed samples were excluded.

The different parameters measured with the help of Vernier caliper were:

Foramen magnum length or Antero-posterior diameter: It was measured from basion which is the median point on the anterior margin of the foramen magnum to opisthion which is the median point on the posterior margin of the foramen magnum (Fig. 1).

Foramen magnum width or Transverse diameter: It was measured between two points of the foramen magnum on most laterally placed margins (Fig. 2).

Foramen magnum index (FM index): It was calculated by Foramen magnum width $X$ 100/ Foramen magnum length.

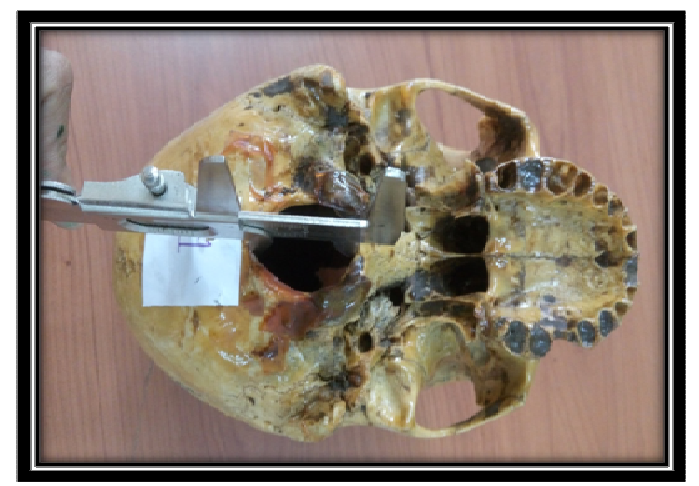

Fig. 1: Photograph showing measurement of antero-posterior diameter of foramen magnum

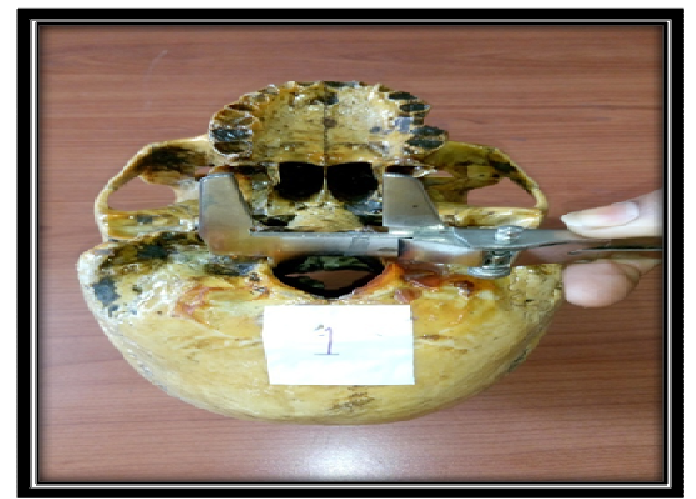

Fig. 2: Photograph showing measurement of transverse diameter of foramen magnum 


\section{OBSERVATIONS AND RESULTS}

The various measurements of foramen magnum were made in 100 dried human skulls of unknown age and sex. The mean antero-posterior diameter of foramen magnum measured in our study was $33.79 \mathrm{~mm}$. The maximum antero-posterior diameter of foramen magnum was $40 \mathrm{~mm}$ and minimum antero-posterior diameter of foramen magnum was $28.2 \mathrm{~mm}$. The mean transverse diameter of foramen magnum was 28.30 $\mathrm{mm}$. The maximum transverse diameter of foramen magnum was $36 \mathrm{~mm}$ and minimum transverse diameter of foramen magnum was $21.5 \mathrm{~mm}$. The mean index of foramen magnum was $84.14 \mathrm{~mm}$ (Table 1).

Table 1: Showing analysis of different parameters of skulls

\begin{tabular}{|l|c|}
\hline Parameter & $\begin{array}{c}\text { Number of } \\
\text { skulls (100) }\end{array}$ \\
\hline $\begin{array}{l}\text { Mean antero-posterior diameter } \\
(\mathrm{mm})\end{array}$ & 33.79 \\
\hline Mean transverse diameter $(\mathrm{mm})$ & 28.30 \\
\hline Mean foramen magnum index & 84.14 \\
\hline
\end{tabular}

\section{DISCUSSION}

The morphometric analysis and shapes of foramen magnum were studied in 100 dried human skulls.

\section{Antero-posterior diameter and Transverse diameter:}

In present study, mean antero-posterior diameter of foramen magnum in 100 dried human skulls was found to be $33.79 \mathrm{~mm}$. The maximum antero-posterior diameter was $40 \mathrm{~mm}$ and minimum antero-posterior diameter was $28.2 \mathrm{~mm}$. The mean transverse diameter was found to be $28.30 \mathrm{~mm}$. The maximum transverse diameter was $36 \mathrm{~mm}$ and minimum transverse diameter was $21.5 \mathrm{~mm}$. Rajkumar et al. (2017) studied 298 dried human skulls of unknown sex and found that the mean antero-posterior diameter of foramen magnum was $33.98 \pm 2.75 \mathrm{~mm}$. The mean transverse diameter of foramen magnum was $28.16 \pm 2.15 \mathrm{~mm}$ [12]. Sampada et al. (2017) studied 78 dried human skulls and found that the mean antero-posterior diameter was $34.84 \pm 2.32 \mathrm{~mm}$ while the mean transverse diameter was $29.39 \pm 1.73 \mathrm{~mm}$ [13]. Rohinidevi and Vimala (2016) studied 38 dried human skulls found that the mean antero-posterior diameter was $34.80 \mathrm{~mm}$. The maximum antero-posterior diameter was $42.18 \mathrm{~mm}$ and minimum antero-posterior diameter was $31.10 \mathrm{~mm}$. The mean transverse diameter was $28.5 \mathrm{~mm}$. The maximum transverse diameter was $32.10 \mathrm{~mm}$ and minimum transverse diameter was $25.20 \mathrm{~mm}$ [14]. Sharma et al. (2015) studied 50 dried skulls of unknown sex and observed mean antero-posterior and transverse diameters of the foramen magnum as $38.75 \mathrm{~mm}$ and $33.44 \mathrm{~mm}$ respectively [15]. Muralidhar et al. (2014) studied on 150 dried human skulls of known sex and found that the mean antero-posterior and transverse diameters of foramen magnum in males were $33.40 \mathrm{~mm}$ and $26.70 \mathrm{~mm}$ respectively. The mean antero-posterior and transverse diameter of foramen magnum in females were $33.6 \mathrm{~mm}$ and $28.00 \mathrm{~mm}$ respectively [16]. Jain et al. (2013) studied on 68 dried human skulls of known sex, found that the mean antero-posterior and transverse diameters of foramen magnum in males were $36.9 \mathrm{~mm}$ and $31.5 \mathrm{~mm}$ respectively. The mean antero-posterior and transverse diameter of foramen magnum in females were $32.9 \mathrm{~mm}$ and $29.5 \mathrm{~mm}$ respectively [17].

The findings of present study are nearly similar to that of Rajkumar et al. (2017) [12], Rohinidevi and Vimala (2016) [14], Sharma et al. (2015) [15] but different from Muralidhar et al. (2014) [16], Jain et al. (2013) [17].

\section{Foramen magnum index:}

In present study the mean index of the foramen magnum was 84.14.

Rajkumar et al. (2017) found the mean value of foramen magnum index $83.14 \pm 6.33$ on 298 dry adult human crania of unknown sex [12]. Singh et al. (2017) found mean value of foramen magnum index as $84.65 \pm 6.32$ in 100 dried human skulls of unknown sex [18]. Vinutha and Shubha (2016) found that the mean FM index of male skull bones was $82.54 \pm 10.49$, whereas in case of female skull bones, it was $83.52 \pm$ 8.93 [19]. Kumar et al. (2015) found that the foramen magnum index was higher in females $(89.01 \pm 6.84 \mathrm{~mm})$ compared to males $(81.75 \pm 5.99 \mathrm{~mm})$ [10]. Sharma et al. (2015) found that the mean value of foramen magnum index was 87.68 on 50 dried human skulls [15]. The data obtained from the present study was compared with the data reported by other authors. After comparison, we observed that our findings were almost similar to that of Singh et al. [18] while different to Sharma et al. (2015) [15] and Kumar et al. (2015) [10]. 


\section{CONCLUSION}

The mean anteroposterior diameter of foramen magnum was $33.79 \mathrm{~mm}$ and the mean transverse diameter was $28.30 \mathrm{~mm}$. These parameters should be taken during craniovertebral and cervical spine surgical procedures. The knowledge of dimensions of the foramen magnum is also helpful in determination of malformations like Arnold Chiari syndrome and in transcondylar approach to make a safe occipital condyles resection. The morphometric analysis of foramen magnum and its variation is important not only for anatomist but also important to the anesthetists, neurosurgeons, orthopedicians and radiologists while planning and performing craniovertebral junction procedures .

\section{REFERENCES}

1. Standring S, Borley NR, Collins P et al. Gray's Anatomy: Head and Neck- External Skull. $40^{\text {th }}$ ed. Spain: Churchill Livingstone; 2008: 415-16.

2. Kanchan T, Gupta A, Krishan K. Craniometric analysis of foramen magnum for estimation of sex. International journal of medical, health, biomedical and pharmaceutical engineering. 2013; 7(7): 111.

3. Oliveira Ed, Rhoton AL, Peace D. Micro surgical anatomy of the region of the foramen magnum. Surg Neurol. 1985; 24:293352.

4. Rouviere $\mathrm{H}$. Anatomia humana descriptiva y topografica.Madrid: Bailly Bailliere, 1956.

5. Radhakrishna SK, Shivarama CH, Ramakrishna A, Bhagya B. Morphometric analysis of foramen magnum for sex determination in South Indian population. NUJHS. 2012; 2(1): 20-22.

6. Sgouros S, Goldin HJ, Hockely AD, Wake MJ et al. Intracranial volume change in childhood. J Neurosurg.1999; 610-616.

7. Rao Prasada PVV. Median (third) occipital condyle. Clinical Anatomy 2002; 15:148-151.
8. Muthukumar N, Swaminathan R, Venkatesh G, Bhanumathy SP. A morphometric analysis of the foramen magnum region as it relates to the transcondylar approach. Acta Neurochir (Wien). 2005; 147:889-895.

9. Gunay $\mathrm{Y}$, Altinkok M. The value of the size of foramen magnum in sex determination. J Clin forensic Med. 2000;7(3):147-148.

10. Kumar A, Dave M, Anwar S. Morphometric evaluation of foramen magnum in dry human skulls, Int J Anat Res. 2015; 3(2):1015-23.

11. Hecht TJ, Horton WA, Reid CS et al. Growth of the foramen magnum in achondroplasia. American Journal of Medical Genetics. 1989; 32: 528-35.

12. Rajkumar, Kattimuthu $P$, Manik $P$ Singh V. Morphometric analysis of the foramen magnum of dry human skulls in North Indian population. Int J Anat Res. 2017; 5(1):3480-84.

13. Sampada PK, Poornima B, Mallikarjun M, Santosh B Sakri. Morphometric and morphological

14. study of foramen magnum in dried human skull bones. Int $\mathrm{J}$ Anat Res. 2017; 5(2.1):3682-86.

15. Rohinidevi M, Vimala V. Morphometric analysis of foramen magnum and variations in its shape in

16. dried human adult skulls, Int J Anat Res. 2016; 4(3):2670-73.

17. Sharma S, Sharma AK, Modi BS, Arshad M. Morphometric evaluation of the foramen magnum and variation in its shape and size: A study on human dried skull. Int J Anat Res. 2015; 3(3):1399-03.

18. Muralidhar $P$ Shepur, Magi $M$, Nanjundappa B, Pavan $P$ Havaldar, Premalatha Gogi, Shaik Hussain Saheb., Int J Anat Res. 2014; 2(1):249-55

19. 17. Jain SK, Choudhary AK, Mishra P. Morphometric evaluation of foramen magnum for sex determination in a documented North Indian sample. JEMDS. 2013; 2(42):809398.

20. 18. Singh KC, Rai G, Rai R. Morphological variations of the foramen magnum in adult human dry skull in eastern UP (India) population. Int J Med Res Prof. 2017; 3(2):205-08.

21. Vinutha SP, Shubha R. Morphometry and sexual dimorphism in foramen magnum: A study of human skull bones. Int $\mathrm{J}$ Anat Res. 2016; 4(3):2593-99. 